\title{
Frequency and risk factors of surgical site infections in general surgery ward of a tertiary care hospital of Karachi, Pakistan
}

\author{
Safia Bibi, Ghulam Asghar Channa, Taranum Ruba Siddiqui, Waquaruddin Ahmed \\ Jinnah Postgraduate Medical Centre, Karachi, Pakistan
}

doi: 10.3396/ijic.V7i3.019.11

\begin{abstract}
The aim of this study was to determine the frequency of surgical site infections and to identify the associated risk factors in general surgery ward of a tertiary care hospital of Karachi. This was a one year cross sectional study conducted in a surgical ward of Jinnah Postgraduate Medical Centre, Karachi. During the study period data was collected on a predesigned questionnaire for all the patients who underwent surgery in the general surgery ward of JPMC and patients were followed for up to 30 days for developments of surgical site infection. Infected cases were identified using CDC, USA definition for Surgical site infections.

In total of 1139 patients surgical procedures were performed in the selected ward during the study period, of which 19 dropped out from the study; of the remaining 1120 patients $82(7.3 \%)$ patients developed surgical site infection. Incidence of surgical site infections was higher in emergency procedures $(13.1 \%)$ as compared to elective procedures $(2.9 \%)$. Incidence related to clean, clean contaminated, contaminated and dirty procedures was $1.5 \%, 2.5 \%, 6.5 \%$ and $21.5 \%$ respectively. Age, wound class, electivity of procedure and diabetes were identified as the main contributing factors towards the development of surgical site infections. Ten patients were readmitted in the hospital after discharge due to SSI.
\end{abstract}

Frequency of SSI in surgical ward of JPMC was lower than other public sector hospitals reported from Pakistan but was much higher as compared to developed countries.

\section{Corresponding author}

Safia Bibi, M.Sc (Microbiology)

Department of Microbiology, Pakistan Medical Research Council, Research Centre,

Jinnah Postgraduate Medical Centre, Karachi, Pakistan.

Telephone number: Office- +92-21-99201355, +92-332-3271256

Home: +92-21-35447346

Email: safia_akuh@yahoo.com 


\section{Introduction}

Hospital acquired infections are not only an important cause of morbidity and mortality but also cause severe economic burden throughout the world. ${ }^{1}$ Risk of these infections is further increased when patients are exposed to invasive procedures. Breach in intact skin and mucosal lining after surgeries provide opportunity to nosocomial pathogens to invade the internal milieu of the body.

Surgical site infections (SSI) are a real problem to the surgeons and are considered as major infection control concern across the world..$^{2-4}$ In the United States, every year SSI develops in $2 \%-5 \%$ of patients, resulting in at least 500,000 infections, 3.7 million excess hospital days and $\$ 1.6$ billion in extra hospital charges. ${ }^{4}$

Surveillance of these infections is a vital step as it provides an insight into the magnitude of problem and hence helps the authorities to take radical measures and therefore curtail these infections. ${ }^{5}$

In many developing countries including Pakistan there is no organized surveillance system to describe routine nosocomial infection rates. Therefore the purpose of this study was to investigate the frequency of SSI and associated risk factors in patients admitted in general surgery ward of a public sector hospital of Karachi.

\section{Patients and Methods}

\section{Study Design:}

A prospective cross sectional study was carried out from December, 2008 to November, 2009.

\section{Study Settings:}

Jinnah Postgraduate Medical Centre (JPMC) is one of the leading tertiary care hospitals of the Pakistan with 1100 beds. It provides the highest degree of medical care to a very large segment of the society. The study was conducted in ward 2 of JPMC which is 48-bed general surgery ward where both elective and emergency procedures are performed.

\section{Sample Size:}

Total 1139 patients who underwent the surgical procedure during the sampling period in Surgical ward 2 of JPMC were included in the study.

\section{Case Definition:}

An SSI case was identified using CDC, USA definition, which states that "infection would be regarded as surgical site infection if it occurs within 30 days of procedure and has at least one of the following: purulent drainage from the wound, pain or tenderness, localized swelling, redness, malodor, fever".

All patients who underwent surgery in the selected ward during the one year study period were included in the study. Preformed questionnaire was filled for each patient to collect necessary data about patient's demographics, clinical diagnosis, surgical procedure, prophylactic antibiotics, post operative antibiotics and any co-morbidity. After surgical procedure, the patients were monitored daily for any signs of infection as per CDC definition. After discharge patients were advised to visit the outpatient department (OPD) once a week to have a check up for any signs of infection. If there were no signs of infection within 30 days of operation, the patient was regarded as having no SSI. Patient who were not able to visit the doctor every week were contacted on phone to ask about their wound condition.

\section{Statistical Analysis:}

The data feeding and analysis was done on computer package SPSS version 11.0. The results are given in the text as mean $(\mathrm{X})$ and standard deviation (S.D) for continuous variables like age and length of stay. Percentages are calculated for categorical variables like gender, type of surgery, infection cases, readmission cases due to SSI.

\section{Results}

During the study period a total of 1139 patients who underwent surgery in Ward-2 of JPMC were enrolled in the study. Nineteen patients $(1.7 \%)$ could not be followed so dropped out from the study. Of the remaining 1120 patients, $624(55.7 \%)$ were males while $496(44.3 \%)$ were females. Mean age of the patients was $35 \pm 17$ years, with a minimum age of 12 years and a maximum of 85 years. Elective procedures contributed for $67.1 \%$ (751) while $32.9 \%$ (369) cases were performed as emergency procedures.

Post operative wound infection (SSI) developed in $82(7.3 \%)$ patients, of these, $48(58.5 \%)$ were males 
while $34(41.5 \%)$ were females. Out of total 82 cases with infection, 54 (65.9\%) surgeries were performed as emergency procedures while 28 (34.1\%) were elective.

Rate of SSI was $5.1 \%, 7 \%, 9 \%$ and $11 \%$ in patients less than 20 years, $21-40$ years, $40-60$ years and above 60 years of age respectively. Although an increasing incidence of SSI is observed with increasing age but statistically it is not significant $(p=0.217)$.

Fourteen $(1.25 \%)$ patients out of total 1120 had diabetes and SSI developed in $4(28.57 \%)$ patients.

Frequency distribution of different surgical procedures along with procedure specific SSI rates during the surveillance period is shown in Table I which shows that SSI is significantly higher in abdominal surgeries as compared to other procedures. Rates of infections in clean, clean contaminated, contaminated and dirty wounds were $1.5 \%, 2.5 \%, 6.5 \%$ and $21.4 \%$ respectively.
Prophylactic antibiotic was given in 970 (86.6\%) cases. Ceftriaxone and ciprofloxacin were predominant antibiotics used for prophylaxis. It was observed that SSI developed in $70(7.2 \%)$ cases where prophylaxis was used and in 12 (8\%) cases without prophylaxes. No significant difference was observed in the rate of SSI between cases receiving ceftriaxone or ciprofloxacin as prophylactic antibiotic.

Mean length of post operative stay after different surgical procedures was 3.2, 4.0, 4.0 and 6.7 days for clean, clean contaminated, contaminated and dirty procedures respectively. Mean length of post operative stay in case of SSI increased to 7.6 days for clean, 9 days for clean contaminated, 12 days for contaminated and 16 days for dirty wounds (Table II). Ten $(0.89 \%)$ patients were readmitted due to SSI during surveillance period.

\section{Discussion}

Surgical site infections are one of the most common forms of nosocomial infections that can complicate the surgical procedure. ${ }^{6}$ Surveillance for SSI is an essential part in control and prevention of SSI.,

Table I: Different surgical procedures and their respective SSI rates

\section{Type Of Surgery}

Abdominal Surgeries

Other Surgeries

Mastectomy

Thyroidectomy

Hernioplasty

Laproscopic Cholecystectomy

Open Cholecystectomy

Fistulectomy

Miscellaneous

TOTAL
Total Number

436

684

51

02

63

0

(0.0)

103

05

49

01

241

11

(4.6)

P-Value 
Table II: Mean \pm standard deviation of length of stay (LOS) after surgical procedure in infected and non infected cases

\begin{tabular}{lccc} 
Procedure & $\begin{array}{r}\text { LOS } \\
\text { Without infection }\end{array}$ & $\begin{array}{r}\text { LOS } \\
\text { With infection }\end{array}$ & p-value \\
\hline Clean & $3.2 \pm 2.1$ & $7.6 \pm 4.1$ & 0.001 \\
\hline Clean contaminated & $4.0 \pm 2.8$ & $9 \pm 5.2$ & 0.001 \\
\hline Contaminated & $4.0 \pm 3.2$ & $12 \pm 6.3$ & 0.001 \\
\hline Dirty & $6.7 \pm 4.5$ & $16 \pm 7.5$ & 0.001 \\
\hline
\end{tabular}

An overall infection rate of $7.32 \%$ was observed in our study which is lower than that reported in Kashmir $(11.3 \%)^{8}$ and Iran $(17.4 \%)^{9}$ but is quite higher as compared to U.S.A $(2.6 \%)^{10}$ and European countries (2.5\%). ${ }^{11}$ Almost similar rates of infection are observed in Nepal $(7.3 \%),{ }^{12}$ Brazil $(5.1 \%)^{13}$ and Philippines (7.8\%). ${ }^{6}$ When compared to other hospitals in our own country these rates are higher than those reported in a private sector hospital of Karachi, ${ }^{14}$ but a comparatively higher incidence of SSI is reported in public sector hospitals of Karachi $(11 \%)^{15}$ and Jamshoro (13\%). ${ }^{16}$ Besides many factors that can contribute to higher SSI rates in Public sector hospitals like inappropriate infection control system, poor practices and indiscriminate use of antibiotics in the absence of proper guidelines, another important factor is the patient characteristics as most of the patients visiting public sector hospitals are from lower socioeconomic group with compromised nutrition and is described as one of the important factors making patients prone to infection. ${ }^{9}$ One other reason for increased rates of SSI might be overcrowding of patients which is a common factor in all public sector hospitals of Pakistan where often extra beds are set up to meet the patient load. Furthermore increased rates of SSI are observed while moving from clean to dirty procedures which are in concordance with other studies but these wound class specific SSI rates were also higher as compared to NNIS (National Nosocomial Infection Surveillance) standards. ${ }^{11,14}$
No relationship was observed between the development of SSI and gender of the patient ( $p=0.593)$ which is in concordance with other studies..$^{9,10}$ Analysis of SSI rates with respect to age showed increasing rates of SSI with increasing age but it was not statistically significant. A higher incidence was observed in patients above 40 years of age. These findings are also similar to other studies as increasing age is usually associated with greater likelihood of certain chronic conditions and decreased immunity with delayed healing. ${ }^{9}$ Increased frequency of SSI was seen in cases that underwent emergency surgery which is in concordance with other studies which show that improper preparation and planning before surgical procedure during emergency leads to higher rates of SSI. ${ }^{9}$

Diabetes is as an important risk factor for the development of wound infections. ${ }^{7}$ This study also shows that diabetic patients are 3.6 times more susceptible to infection as compared to non diabetics. We could not establish any association between use of prophylactic antibiotic and development of SSI, in fact the frequency of postoperative infection was similar in those that were given prophylactic antibiotics and those that were not given. Solangi et al. in 2004 reported that use of prophylactic antibiotic in all clean procedures should be avoided as they could not observe any influence of prophylactic antibiotic use and SSI rates in clean procedures. ${ }^{17}$ 
It was seen that SSI was associated with a significant increase in postoperative hospital stay and the readmissions in 10 cases. The prolonged hospital stays associated with infection and readmissions results in the psychological stress to the patient along with added cost to the patient as well as on hospitals. ${ }^{18}$

\section{Conclusion:}

Frequency of SSI in surgical ward of JPMC is comparable to developing countries but is higher than developed countries. A continuous long term surveillance system should be established to identify more risk factors, along with development of hospital infection control committees and officers who should look at these day to day issues of infection and provide necessary guidelines regarding safety measures for reducing SSI.

\section{Acknowledgement:}

We are grateful to Pakistan Medical Research Council for providing us funds to make this study possible. Furthermore we extend our thanks to all the medical and nursing staff of surgical ward 2 for their cooperation in carrying out the study.

\section{References:}

1. Emori TG, Gaynes RP. An overview of nosocomial infections, including the role of the microbiology laboratory. Clin Microbiol Rev 1993; 6(4): 428-442.

2. Lichtenstern C, Schmidt J, Knaebel HP, Martin E, Bochler MW, Weigand MA. Postoperative bacterial/fungal infections: A challenging problem in critically ill patients after abdominal surgery. Dig Surg 2007; 24: 1-11. http.dx.doi. org/10.1159/000099009

3. Collier M. Recognition and management of wound infections. World Wide wound 2004. http://www.worldwidewounds. com/2004/january/Collier/Management-of-Woundinfections.html
4. Lapsley HM, Vogels R. Quality and cost impacts: prevention of post-operative clean wound infections. Int / Health Care Qual Assur 1998; 11: 222-231. http.dx.doi. org/10.1108/09526869810243935

5. Shojoei H, Borjian S, Shooshtari PJ, Shirani S. Surveillance of clean surgical procedures: An indicator to establish a baseline of a hospital infection problem in a developing country, Iran. Ind J Surg 2006; 68(2): 89-92.

6. Siguan SS, Ang BS, Pala MI, Baclig MR. Aerobic surgical infection: A surveillance on microbiological etiology and antimicrobial sensitivity pattern of commonly used antibiotics. Phil J Microbiol Infect Dis 1990; 19(1): 27-33.

7. Tahir MS. Surgical wounds and prevention of infection in the hospital. The Professional 1995; 2(3): 173-181.

8. Mustafa A, Bukhari A, Kakru DK, Tabish SA, Qadri GJ. Incidence of nosocomial wound infection in postoperative patients at a teaching hospital in Kashmir. JK-practitioner 2004; 11(1): 38-40.

9. Razavi SM, Ibrahimpur M, Kashani AS, Jafarian A. Abdominal surgical site infections: incidence and risk factors at an Iranian teaching hospital. BMC Surg 2005; 5(2) (doi:10.1186/14712482-5-2)

10. Gaynes RP, Culver DH, Horan TC, Edwards JR, Richards C, Tolson JS. Surgical site infection rates in the United States, 1992-1998: the national nosocomial Surveillance System basic SSi risk index. Clin Infect Dis 2001; 33: s69-s77. http. dx.doi.org/10.1086/321860

11. Leaper DJ, van Goor H, Reilly J, et al. Surgical site infectionsa European perspective of incidence and economic burden. Int Wound I 2004; 1: 247-273. http.dx.doi.org/10.1111/ j.1742-4801.2004.00067.x

12. Giri BR, Pant HP, Shankar PR, Sreeramareddy CT, Sen PK. Surgical site infection and antibiotics use pattern in a tertiary care hospital in Nepal. P Pak Med Assoc 2008; 58(3): 148151.

13. Medeiros AC, Neto TA, Azevdo GD, Vilar MJP, Pinheiro LAM, Neto JB. Surgical site infection in a University hospital in Northeast Brazil. Braz J Infect Dis 2005; 9(3): 310-314. http. dx.doi.org/10.1590/S1413-86702005000400007

14. Pishori TS, Siddiqui AR, Ahmed M. Surgical wound infection surveillance in general surgery procedures at a taching hospital in Pakistan. Am J Infect Control 2003; 31: 296-301. http.dx.doi.org/10.1067/mic.2003.7

15. Sattar I, Aziz A, Rasul S, Mehmood Z, Khan A. Frequency of infection in cholelithiasis. I Coll Physicians Surg Pak 2007; 17(1): 48-50.

16. Sangrasi AK, Leghari AA, Memon A, Talpur AK, Qureshi GA, Memon JM. Surgical site infection rate and associated risk factors in elective general surgery at a public sector medical university in Pakistan. Int Wound / 2008; 5: 74-78. http. dx.doi.org/10.1111/j.1742-481X.2007.00365.x

17. Solangi RA, Memon GA, Dahri FJ, Qazi ARR, Yousifani SA. Does every clean surgical wound need antimicrobials? Medical Channel 2004; 10(3): 41-43.

18. Geubbels ELPE, Groot JM, Berg JMJ. Boer AS. An operating surveillance system of surgical site infections in th Netherland: Results of the PREZIES national surveillance network. Infect Control Hosp Epidemiol 2000; 21: 311-318. http.dx.doi. org/10.1086/501762 